\title{
MIGRACIÓN: \\ RIESGOS Y OPORTUNIDADES
}

Monseñor Vicente Cisneros Durán

Arzobispo de la Arquidiócesis de Cuenca

\section{INTRODUCCIÓN}

\section{REALIDAD DEL FENÓMENO DE LA MIGRACIÓN:}

V

ivimos una época muy especial en nuestra patria ecuatoriana y más particularmente en la zona austral, en que cada día asistimos al ÉXODO DE MILES DE COMPATRIOTAS HACIA OTROS PAÍSES Y REGIONES. También se da el fenómeno de la llegada de campesinos a la ciudad. Particularmente la salida de nuestros coterráneos al extranjero se realiza, en general, por caminos ilegales y llenos de riesgos y peligros.

En los últimos años hemos leído, con preocupación y angustia, las NOTICIAS ALARMANTES SOBRE LAS VICISITUDES que padecen nuestros compatriotas quienes, llevados de ilusión y esperanza de días mejores en otros lares, arriesgan todo para cumplir con sus sueños. Se DESORGANIZAN SU HOGAR Y SU FAMILIA; se da el abandono de los hijos o esposa; los niños son los que más sufren: se afectan sicológicamente y por ende su rendimiento en la escuela es bajo; se llega a la venta o hipoteca de sus BIENES; la VIDA corre tal PELIGRO que, a veces, termina en muertes trágicas en alta mar, en un desierto, en un río, en la bodega de un barco o en una frontera; por ejemplo fue trágica la muerte de doce ecuatorianos en un accidente fatal en Lorca, Murcia, España; los migrantes pierden la LIBERTAD al ser detenidos y encerrados en mazmorras inhumanas; hay el DESFASE CULTURAL Y RELIGIOSO; es tremendo el HACINAMIENTO EN VIVIENDAS INFRAHUMANAS; es común la EXPLOTACIÓN DE LOS DADORES DE TRABAJO, que es, a veces, humillante y mal pagado, sin contrato y sin condiciones dignas; hay ocasiones en que se mendiga el pan de cada día; es alarmante la inmisericorde actuación de los llamados "COYOTES” hombres y mujeres; es frecuente el retorno obligado o sea la DEPORTACIÓN al país, sin 
dinero y sin salud; se contraen ingentes DEUDAS que quedan pendientes por muchos años o que les llevan a la insolvencia.

Son múltiples las CAUSAS para haber llegado a esta situación. Entre ellas, especialmente en los últimos años, están el EMPOBRECIMIENTO, LA MISERIA O LA DESOCUPACIÓN DE BUENA PARTE DE LOS ECUATORIANOS. La realidad del país vino a agravarse con el congelamiento de fondos y otros fenómenos, como consecuencia de las políticas macroeconómicas, la globalización, la dolarización y la inestabilidad económica, social y política.

Por cuanto en el fenómeno de la migración no todo es negativo, me permito presentar junto a los riesgos y a las situaciones negativas, que son más palpables y dolorosas, también un listado aproximado de oportunidades, que si bien no logra agotar el tema, es un acercamiento a la realidad que vivimos.

\section{ALGUNOS RIESGOS:}

Riesgos para el individuo: Debilitamiento de sus valores familiares, culturales, religiosos, sociales. Soledad, desubicación, depresión. Peligro de repatriación. Contracción de ingentes deudas. Peligro de la vida. Discriminación en una sociedad extraña. Desarraigo, inseguridad, explotación. Anonimato. Posible prostitución de la mujer migrante con el peligro latente de contraer enfermedades como el SIDA. Fracaso de algunos migrantes. Impacto cultural en la forma de vestirse (tienden a dejar la pollera), baja autoestima, bajo rendimiento, rebeldía, aislamiento, individualismo, sobrevaloración de lo internacional. Como dice Armando Albornoz Vintimilla, "El dinero que envían los migrantes, muchas veces es usado por sus hijos o nietos en diversiones malsanas, incluso en el consumo de todo tipo de drogas y licores" ("El Mercurio, 18 de junio de 2001, Pág. 4A)

En vista de estos y otros riesgos se ha llegado a afirmar que "los más pobres son los más propensos a emigrar".

Riesgos para la familia: Desorganización y desintegración familiar. Infidelidad matrimonial de hombres y mujeres. Abandono de los hijos. Falta de cariño paternal. Descuido de obligaciones fami- 
liares. Descuido de la labor educativa en los hogares. Nuevas uniones ilegales. Intentos de suicidio de algunos hijos que se quedan en el país. Jóvenes que se quedan y reciben mucho dinero que malgastan en drogas, alcohol, artículos suntuarios. Complejo de superioridad basado en el mucho dinero fácil y otros riesgos.

Hay casas recién construidas y abandonadas, a medio construir, construidas con planos elaborados de acuerdo a las órdenes enviadas desde el exterior. Los hijos solo pueden comunicarse con sus padres a través de vídeos, fotografías o por teléfono y al no contar con la figura paterna, su comportamiento se ve seriamente afectado. El abismo generacional que separa a los nietos que se quedan al cuidado de sus abuelos es una gran dificultad.

Riesgos para la patria y la sociedad: Fuga de fuerzas laborales jóvenes. "Muchas fábricas de Cuenca trabajan en su mayoría con personal femenino". "Desangre de fuerzas productivas en nuestros pueblos". "Fuga de cerebros". Pérdida de recursos invertidos en la educación de los migrantes. Mayor crisis económica. Pérdida de la identidad patria. Algunos migrantes ocasionan serios problemas escolares, de riesgo sanitario, carga de asistencia social, prejuicios raciales, conflictos y diferencias lingüísticas.

Riesgos para la Iglesia: Notable disminución de su personal de pastoral. Pérdida de recursos invertidos en la formación. Debilitamiento de los principios morales cristianos. Degradación moral y religiosa. Pérdida del sentido comunitario. Paso a ideologías y sectas religiosas extrañas. Hay migrantes que antes de abandonar el país visitan a ciertos "curanderos" para que les realicen una "limpia" para conseguir éxito en su viaje, actividad que la complementan con las misas de acuerdo a su devoción.

\section{ALGUNAS OPORTUNIDADES:}

Oportunidades para el individuo: Mejoramiento de la situación económica. Enriquecimiento con una nueva cultura. Autorrealización personal. Nuevo idioma. Tener un respaldo económico en la 
vejez. Comprar terrenos, autos, casas en la ciudad, maquinaria agrícola, animales. Prestar dinero. Invertir en negocios.

Oportunidades para la familia: Mejor situación económica para atender salud, educación, vestido, alimentación y bienestar. Construcción de vivienda propia. "Las familias de migrantes... deben tener la posibilidad de encontrar siempre en la Iglesia su Patria". (Familiaris Consortio 77).

Las mujeres migran para reunirse con sus maridos y salvar el matrimonio. La mujer ha asumido nuevos roles a nivel familiar y social por la ausencia de los varones.

Oportunidades para la patria y la sociedad: Aporte a la economía del país. Intercambio cultural. Inversión en pequeños negocios y proyectos productivos. "La historia del hombre es historia de migraciones". "Existe un ingreso bastante alto para el país en las remesas de los migrantes, el segundo más importante después del petróleo, según los cálculos del Banco Central. Un buen porcentaje se dirige a la región austral". (Juan Fco. Beltrán R. "El Mercurio", domingo 6 de mayo, 1B) Sin embargo, "Francisco Salgado sostiene que ese dinero no es canalizado adecuadamente, porque por lo general se lo utiliza en la compra de bienes raíces, objetos suntuarios y a veces en una simple acumulación que ni siquiera puede ser considerada como ahorro" (Ibíd).

Oportunidades para la Iglesia: Expresión y vivencia de la universalidad de la Iglesia. El migrante no es extraño para la Iglesia en ninguna parte: todos los bautizados son sus hijos. "La historia de nuestra fe es historia de migraciones". Los catequistas y animadores son agentes de pastoral en el extranjero. "Las migraciones humanas son un desafío a la fe y al amor de los creyentes" ha escrito el Padre Claudio Ambrozio, Misionero Escalabriniano.

\section{COMUNICACIÓN Y DESARROLLO ECUADOR-ESPAÑA, NUE- VA OPORTUNIDAD}

Desde el domingo 22 de abril del año 2001, de 10:00 a 11:00 y bajo el lema de "No levantar la nostalgia sino la esperanza", doce emisoras comunitarias en el Ecuador y cuatro en Espa- 
ña, simultáneamente desde Quito y Madrid, transmiten cada domingo el programa, de radio "Callos y Guatitas". En dicho programa, que también incluye noticias sobre los migrantes, se intercomunican 18 provincias del Ecuador con la capital de España. Este espacio forma parte del "Plan Migración, Comunicación y Desarrollo Ecuador-España", que comprende seis líneas de trabajo: comunicación, asesoría en educación, derechos y ciudadanía, proyectos de desarrollo, intermediación financiera ética, canje de deuda externa por desarrollo e investigación.

En este proyecto participan siete instituciones, de las cuales cuatro son ecuatorianas: ALER, el Fondo Ecuatoriano PopuIorum Progressio, FEPP, la Pastoral Social de la Conferencia Episcopal y el ILDIS. Por España intervienen: la Coordinadora de Radios Comunitarias, Cáritas y el Grupo de "Deuda Externa, deuda eterna".

Para apoyar esta comunicación y con la coordinación de la Vicaría de Pastoral Social, se está preparando el proyecto de instalación de tres cabinas de radio en la región austral para lograr una mejor intercomunicación con los distintos países donde se han concentrado mayoritariamente nuestros migrantes, para una tarea de orientación, asesoramiento y formación en distintas áreas del complejo tema de la migración.

Vemos que dentro de los ejes del plan se encuentra el impulso a los proyectos de desarrollo. Para ello, el FEPP ofrecerá capacitación a las familias de los migrantes para que puedan instalar sus pequeñas empresas en la rama que elijan. De esta manera se puede invertir de mejor forma el dinero que les envían sus familiares.

\section{FUTURO SUSTENTABLE: UN DESAFÍO LA IGLESIA ANTE UNA MIGRACIÓN POSITIVA}

La Conferencia Episcopal señala: "La migración abre nuevos horizontes sociales y culturales que enriquecen humanamente a muchos migrantes; redefine identidades y genera procesos de agrupación y organización de "colonias" tanto en el país como en el exterior. Se van fortaleciendo también instancias de acogida solidaria y de presión social frente a las políticas discriminatorias". (P.G. 167) 


\section{JUAN PABLO II Y LA MIGRACIÓN}

Con el fin de proyectarnos hacia el desafío que presenta el futuro sustentable de la migración, permítaseme anotar algunos títulos de los temas desarrollados, en los últimos años por el Papa Juan Pablo Il con ocasión de la Jornada Mundial de las Migraciones:

"La familia y la migración". "La acogida y la integración del extranjero: un deber institucional para la parroquia". "La caridad, motor de la atención al migrante. La hospitalidad al extranjero. Preferencia por los pobres y marginados". "Acoger al emigrante con la actitud gozosa de quien reconoce en él el rostro de Cristo". "Compromiso cristiano de solidaridad y promoción humana de los emigrantes". "Ejemplo de Cristo. La fe y las obras". "La fe actúa por medio de la caridad". "Solidaridad y protección para la mujer implicada en el fenómeno migratorio". "Es preciso que el Estado defienda las familias de los inmigrantes de la marginación y el racismo". "Ayudar a los migrantes a defenderse del proselitismo de las sectas". "La realidad de la migración y vocación de la Iglesia". "Contemplar a los migrantes a la luz de María". "Los laicos católicos y las migraciones". "La vida cristiana y la integración eclesial". "Migraciones económicas". "Migrantes irregulares".

De estos mensajes se desprende la necesidad de políticas de acogida e integración de los migrantes por parte de los países receptores. En donde hay ambiente cristiano entran como apoyo la caridad, la hospitalidad, la fraternidad, el compromiso cristiano de solidaridad y promoción humana de los migrantes, la protección preferente a la mujer, el destierro del racismo y la marginación, la ayuda a las familias y la misma fe.

Me permito transcribir aquí un aparte del Mensaje Pastoral difundido por "Telerama" a nivel nacional en el Programa "La Voz del Pastor" con el tema: "Desafío de las migraciones", del 14 de enero del año 2001, basado en el mensaje pontificio con ocasión de la Jornada Mundial de la Paz: "La ACOGIDA a los migrantes por parte de los países que los reciben valora la calidad de DIÁLOGO entre las diferentes culturas. A veces no se definen los derechos y deberes de los que acogen y de los aco- 
gidos. El proceso migratorio ha enriquecido algunas civilizaciones. Ha sido posible una convivencia". "Los emigrantes han de ser tratados siempre con el respeto debido a la dignidad de toda persona humana".

También Juan Pablo II nos insta al respetar las CARACTERÍSTICAS CULTURALES DE LOS EMIGRANTES, siempre que no se opongan a los valores éticos universales de la ley natural y a los derechos humanos fundamentales. Bien común, identidad, diálogo, importancia de las culturas, "equilibrio cultural", respeto a la "fisonomía cultural" y al "ethos" o valor moral, a la libertad y a la conciencia de las personas, a la lengua, tradiciones y valores de la patria de origen.

\section{LA IGLESIA EN EL ECUADOR Y LA MIGRACIÓN}

En consonancia con estos anhelos la Iglesia en el Ecuador, según la programación realizada para los próximos diez años en el Plan Global de Pastoral, se ha comprometido a "buscar caminos para que el Estado establezca leyes de protección a los migrantes y firme acuerdos internacionales que permitan un trato humano y digno a los migrantes" (P.G. Prog. 133); a "establecer acuerdos interdiocesanos dentro del país y con diócesis de otros países, para crear redes de solidaridad, acogida, orientación y protección a los migrantes" (P.G. Prog. 134); a "impulsar proyectos que integren a los migrantes ecuatorianos en el exterior, para que aporten a la sociedad su identidad cultural y cristiana, para que favorezcan la comunicación e información desde y hacia los migrantes" (P.G. Prog. 135). También se compromete a acompañar a las familias de los migrantes, en especial a los niños, a favorecer el encuentro y la mutua ayuda entre ellas y a facilitar su relación con las colonias de migrantes" (P.G. Prog. 136). Asimismo, fortalecerá las instancias de acogida y acompañamiento a la creciente inmigración hacia nuestro país"; formará agentes de pastoral especializados para el acompañamiento a los migrantes dentro y fuera del país" (P.G. Prog. 138); apoyará a los migrantes enviando sacerdotes y religiosas a los lugares de inmigración y asumirá otras iniciativas de acuerdo a la realidad local y a las posibilidades. 


\section{VISIÓN RELIGIOSA DE LA MIGRACIÓN}

Según las reflexiones realizadas en la Vicaría de Pastoral Social, aquí transcribimos algunos pensamientos de carácter teológico bíblico: "La Iglesia desde su experiencia milenaria y su vivencia teologal tiene un mensaje para el mundo de la migración y una práctica de solidaridad con los migrantes; doctrina y práctica que debe ser valorada e incorporada a la visión y misión de la construcción de un mundo globalizado donde haya más justicia y solidaridad. Desde su prehistoria de raíces hebreas y judías, la Iglesia ha aprendido que la naturaleza del ser humano no se realiza en una vida sedentaria en la que el objetivo es defender el bienestar conseguido a costa del sufrimiento de los otros".

"El Antiguo Testamento es testigo de un proceso migratorio que duró mil años desde que Abraham salió de su tierra natal hasta que sus descendientes lograron instalarse en la tierra de Canaán. El pueblo de Israel testimonia sus experiencias de desarraigo, de destierro, de vuelta a la patria, de diáspora, de enfrentamiento a los imperios, de lucha y resistencia cultural. A partir de allí nuestros antepasados en la fe desarrollaron una teoría y una práctica de solidaridad y justicia: Dios es el defensor del migrante, el Estado debe proteger al extranjero, la hospitalidad y la solidaridad con el migrante son partes sustanciales de una ética de justicia y solidaridad".

Podríamos decir que el Nuevo Testamento es fruto de la migración divina de Jesucristo que vino a poner su tienda de campaña entre nosotros. "Jesús puso los fundamentos de una Iglesia como comunidad alternativa donde nadie debe sentirse extranjero, sino hermano". El cristianismo propone una ciudadanía universal en la que todo hijo de Dios tenga los mismos derechos. "La Iglesia se hizo migrante y misionera para llevar la Buena Nueva a todos los rincones de la tierra".

\section{SOLIDARIDAD: UNA ACTITUD CRISTIANA Y ECLESIAL}

"En Estados Unidos, España, Italia nuestros compatriotas ecuatorianos encuentran en los Obispos, en organizaciones cató- 
licas y sociales, en las Cáritas y en las parroquias, acogida, asesoría y solidaridad. El documento Pontificio "La Iglesia en América", que fue el fruto del Sínodo para nuestro continente, exhorta a las Conferencias Episcopales, a las Diócesis y a las parroquias a aunar esfuerzos para trabajar de modo más coordinado y eficaz a favor del mundo de la migración".

La Iglesia se encuentra promoviendo una campaña para captar, a través de sus cooperativas, el dinero enviado por los migrantes para que pueda ser invertido en proyectos comunitarios de producción. Sin embargo, se vislumbra que la inversión de los recursos especialmente en los Estados Unidos, por la seguridad y por la situación económica se van quedando en ese mismo país, ya que también los intereses han disminuido notablemente en todas partes. Se hacen esfuerzos para transformar la deuda de los llamados "chulqueros" en deuda bancaria. Tal es el caso del Convenio entre la Mutualista Azuay y la Vicaría de Pastoral Social de la Arquidiócesis de Cuenca. Sin embargo, son procesos que necesitan tiempo, convicción y confianza.

Lamentablemente parece que los proyectos de construcción que los migrantes impulsaron tan vigorosamente y que son más visibles en el austro, han tenido una disminución, si bien aún es notable.

\section{COMPROMISO DE LA ARQUIDIÓCESIS DE CUENCA CON LA MIGRACIÓN}

Como señala un comunicado de la Pastoral Social, "la Arquidiócesis de Cuenca ha sido pionera en el Ecuador en el trabajo a favor de los migrantes. Interpelada por la realidad de siglos y especialmente de las últimas décadas, ha sido sensible a la llamada de Dios a responder a las necesidades de su feligresía en permanente movimiento interno y externo. La Vicaría de Pastoral Social, apoyada por el Departamento de Movilidad Humana de la Conferencia Episcopal Ecuatoriana y en concordancia con el Departamento de Movilidad Social -CEPAM- del Consejo Episcopal Latinoamericano, CELAM, hermanada con su similar de la Diócesis de Azogues, ha desplegado un incesante trabajo con los migrantes y sus familias. Durante cerca de una década ha sido la única instan- 
cia a donde han podido acudir quienes han sufrido los efectos negativos de la migración".

"La realidad de la migración para la Iglesia del Azuay es sin duda uno de los mayores retos pastorales, pero constituye también un desafío para toda la sociedad y sus instancias públicas y privadas. La Iglesia sola podrá desarrollar una amplia labor de solidaridad, pero sin el concurso del Estado, de los poderes locales y de toda la sociedad organizada, no será posible avanzar en la línea de la justicia".

En la Pastoral Social de la Arquidiócesis existen proyectos que tratan de atender las necesidades de los migrantes y sus familias a través del programa "solidaridad". Por ejemplo hay un proyecto denominado "Pastorales Sociales Parroquiales" que busca "impulsar las organizaciones de los migrantes y apoyar sus luchas por sus derechos y por conseguir una mayor presencia de los ecuatorianos en la sociedad y en las parroquias. Las bases de este proyecto estarían constituidas por "comités de Solidaridad" en Toronto y New York, cuyos objetivos son: a) mayor presencia en las parroquias, participando en ellas con sus derechos y obligaciones; b) Prestar servicios de solidaridad a los recién llegados y a quienes han caído en desgracia; c) Mantener vivas las tradiciones culturales y religiosas del pueblo; d) Sumarse a la lucha por los derechos de los migrantes; e) Colaborar con los proyectos de solidaridad a ejecutarse por medio de la Pastoral Social Arquidiocesana".

\section{LA SOCIEDAD Y EL ESTADO ANTE LA MIGRACIÓN}

Es importante la ejecución de políticas internacionales previstas en los convenios bilaterales, el establecimiento de medidas jurídicas y el cumplimiento de las leyes de protección a los migrantes.

En este aspecto, como señala el folleto: "Somos migrantes, tenemos derechos", (Quito, enero de 1997, pág. 28.): "La sociedad ecuatoriana es indiferente a los diversos problemas en torno a la migración". Existe un deterioro de los derechos humanos de la mayoría de los migrantes y es nuestro deber reconocer esta problemática y los derechos de los migrantes, para lo cual debemos: 
Participar todos en la solución de los problemas de la migración, especialmente las autoridades a través de políticas nacionales.

Procurar que se ratifique la "Convención Internacional sobre la Protección de los Derechos de todos los Trabajadores Migratorios y sus Familiares" y otros documentos.

A este respecto se debería aplicar el marco jurídico señalado en el Art. 17 de la Constitución que dice: "El Estado garantizará a todos sus habitantes, sin discriminación alguna, el libre y eficaz ejercicio y el goce de los derechos humanos establecidos en esta Constitución y en las declaraciones, pactos, convenios y más instrumentos internacionales vigentes". Como señala la Conferencia Episcopal, "el problema de la migración no es afrontado con seriedad por los gobiernos" (P.G. 166).

Este fenómeno, no obstante sus sombras, puede "contribuir a construir una sociedad con mejores posibilidades para la promoción de sus habitantes, especialmente del austro, donde se experimenta con mayor fuerza". La aspiración sería convertir "el fenómeno migratorio en una oportunidad para crear un futuro viable y próspero en el contexto de un mundo globalizado más justo y más humano".

De hecho "al analizar las oportunidades, estas van a ser tales solo en el supuesto de que quienes tienen que tomar las decisiones sobre el presente y futuro del país, lo hagan en el sentido de hacer viable la economía, la seguridad y la justicia para todos los ecuatorianos sometidos hasta ahora a un proceso de empobrecimiento permanente. El Estado está en el deber de diseñar políticas que reactiven las economías de las mayorías que hoy no son los que están en extrema pobreza, sino la que antes constituía la clase media que es la que está migrando y continuará haciéndolo..."

\section{GLOBALIZACIÓN Y MIGRACIÓN}

La migración ha adquirido una nueva significación. Día a día se convierte en un factor global de las relaciones internacionales.

Como señala el Padre Fernando Vega, Vicario de Pastoral Social de Cuenca, "La migración, como fenómeno mundial, hay 
que considerarla como resultado de la acumulación lenta y sostenida de tensiones y desequilibrios producidos durante el siglo pasado. Pues el desequilibrio poblacional y económico entre los países del norte y del sur se ha ido profundizando progresivamente. La riqueza del planeta se ha ido concentrando en pocas manos en los países desarrollados, mientras que los países del tercer mundo han sufrido un proceso de empobrecimiento cada vez más creciente, causado por las reglas políticas, económicas y comerciales a las que se las ha sometido desde las metrópolis colonialistas. Por esta razón los poderes locales, casi siempre se encuentran vendidos a los poderes del capitalismo y ajenos a los verdaderos intereses de sus pueblos ..."

Y continúa: "La globalización del planeta, que ha sido iniciada por la tecnología de los poderosos, va a ser completada por la migración de los pobres. La globalización solo será tal cuando esté al servicio de todos los seres humanos en función de conseguir una vida más digna y equitativa para todos. Por eso, si los países ricos (del primer mundo) y los gobiernos de los países pobres (del tercer mundo), les han negado a los pobres un camino de desarrollo y bienestar, esa población empobrecida ha iniciado, especialmente desde la década de los setenta, un éxodo de sus patrias. En la actualidad de manera explosiva y masiva se está buscando nuevos caminos de sobrevivencia. Millones de africanos, latinos y asiáticos están presionando las fronteras de los países de Europa y América del Norte e invadiendo los controles fronterizos..."

\section{LA SOLUCIÓN ES TAREA DE TODOS}

Se llega a formular un interrogante que es un desafío para todos nosotros: ¿CÓMO SOLUCIONAR ESTE INMENSO PRO$B L E M A$ ? Ciertamente que la respuesta no es fácil por cuanto la REALIDAD es sumamente compleja y llena de aristas y dificultades. La solución depende de muchos FACTORES, PERSONAS E INSTITUCIONES. Sin embargo, creemos que es misión de la Iglesia, que somos nosotros, comprobar la realidad de los hechos, reflexionar a la luz de la palabra de Dios y del mensaje del evangelio y encontrar soluciones solidarias y fraternas. Hay que eliminar los efectos negativos y fomentar los positivos. Es importante llegar 
a la convicción de que, por ejemplo, un dinero conseguido con tanto sacrificio y sudor debe servir para emprender en PROYECTOS PRODUCTIVOS O EN INICIATIVAS RENTABLES. No se lo puede malgastar o despilfarrar. Con miras al futuro es necesaria la preparación de niños y jóvenes para enfrentar al mundo y a la cultura adveniente, con sus nuevos desafíos y dificultades.

Por consiguiente, apoyemos las iniciativas de los organismos que se ocupan de los migrantes, como es el caso de nuestra Pastoral Social Arquidiocesana y que van emprendiendo en proyectos especiales en beneficio de la atención a los hermanos que han dejado el país y más aún a quienes resultan víctimas de esa situación. El llamado "dólar solidario" y todo aporte personal, comunitario y de toda índole van a servir para ayudar a quienes son víctimas de la migración.

No podemos quedar indiferentes ante el fenómeno de la migración. Todos, gobernantes, Iglesia, organizaciones y demás estamentos de la sociedad estamos llamados a arrimar el hombro y realizar todos los esfuerzos para que se eviten los riesgos y se aprovechen las oportunidades que presenta la realidad migratoria de nuestro país, para que este fenómeno y realidad asegure un futuro sustentable a nuestros migrantes y a la patria. 